\title{
Misión del bibliotecólogo de hoy
}

\author{
Rosalía Quiroz de García \\ Directora de la EAP de Bibliotecología
}

Abordar el término misión nos lleva aproximarnos a lo que en su momento señalara el eminente filósofo Ortega y Gasset: "Misión significa, por lo pronto, lo que un hombre tiene que hacer en su vida [...], la misión es algo exclusivo del hombre. Sin hombre no hay misión [...]. Las carreras o profesiones son tipos de quehacer humano que, por lo visto, la sociedad necesita. $Y$ uno de éstos es desde hace un par de siglos el bibliotecario"1. Mensaje vigente que resume con claridad y sencillez lo que entendemos por misión y formación profesional, aspectos a tratar dentro del marco de la formación profesional del licenciado en bibliotecología y ciencias de la información.

La información tFaducidos em conociniento humano, ha ido dejando huellas con el correr del tiempo las mismas que han sido plasmadas o registradas para su mejor conservación en todo tipo de soportes, sean éstos de carácter textual (libros, revistas), audiovisual (discos, vídeos, etc.), magnético, etc. información que continúa incrementándose en proporción directa al avance de la ciencia y la tecnología, constituyendo así la gran memoria de la humanidad, depositadas o almacenadas en sus inicios en bibliotecas, archivos, luego en centros de documentación, bases de datos, banco de datos, centros de referencia, etc. en suma, en todo tipo de unidades de información. La información constituye el objeto de estudio de las ciencias de la información, y como tal ha sido definido ampliamente por la UNESCO: "Elementos sim-

1 Ortega y Gasset, José. Misión del bibliotecario. Madrid: Revista de Occidentes, 1962, pp. $51,56-57$. 
bólicos, datos o documentos utilizados para comunicar el conocimiento científico, técnico o cultural, independientemente de su carácter (numérico, textual, icónico, etc.), de los soportes materiales, de la forma de presentación, etc. Se refiere tanto a la sustancia o contenido de los documentos como a su existencia material; también se emplea este término para designar tanto el mensaje (contenido y forma) como su comunicación (acción). Cuando es necesario se distingue entre información bruta (hechos, conceptos, representaciones) y los documentos en los que está registrada".

Por otro lado, las ciencias de la información, disciplina científica reciente, que no debe ser confundida con las ciencias de la comunicación, fue definida por primera vez en 1961-62 por el Instituto de Tecnología de Georgia, EE.UU: "Es la ciencia que investiga las propiedades y el comportamiento de la información y las leyes que gobiernan los flujos de información y su procesamiento para su óptimo acceso y utilización. Proceso que incluye la generación, la diseminación, la recolección, la organización, el almacenamiento, la recuperación, la interpretación y el uso de la información".

Consecuentemente, la esencia de la labor profesional del bibliotecólogo y especialista de las ciencias de la información, es organizar la información contenida en diferentes soportes, los mismos que requieren de un manejo profesional desde su selección, adquisieión, organización, almacenamiento, recuperación y transferencia, hasta Legar at servicio de usuarios, tanto estudiantes, educadores, investigadores, politicos, juristas, industriales, gerentes, etc permitiéndoles elêvar su nivefCultural y en otros, una adecuada y oportuna toma de decisiones en el ámbito de sus actividades, compatibilizando con quienes sostienen que "la transferencia de información científica y técnica es condición primaria e indispensable de todo progreso o desarrollo... "2 y como tal: "la información es un recursos económico con efecto multiplicador muy superior a otros recursos, que no se gasta y que puede duplicarse y trasmitirse a cualquier parte con costos relativos mínimos" 3 .

Sin embargo, la función del bibliotecólogo profesional y su quehacer en

2 Guinchat, Claire. Introducción general a las ciencias y técnicas de la información y documentación. Madrid: UNESCO, 1990, p. 22.

3 Fernández-Aballi, Isidro. "La información: un recurso esencial para el desarrollo". En. INFOLAC, Vol. 9, $\mathrm{N}^{\circ} 3,1996$, p. 4. 
el mundo de la cultura, aún no es entendida en su total dimensión por los diferentes sectores de la sociedad, sorprende el desconocimiento que existe en considerable números de profesionales de otras áreas quienes, sin ninguna duda, durante toda su formación académica y desarrollo profesional necesitaron y aún siguen necesitando de información, dentro o fuera de una biblioteca u otro tipo de Unidad de Información; cuando manifiestan, acaso ¿para conducir una biblioteca se requiere estudiar?, respuesta que en la práctica equivale a considerar que la labor del bibliotecólogo, probablemente asociado a su denominación, sólo se limita a ordenar libros en las estanterías y hacer las veces de un auxiliar (el préstamo de material bibliográfico), y como tal, puede prescindirse de sus servicios sin mayores implicancias en la marcha de la institución, nada más errado y con nefastas consecuencias que esta concepción.

El rol social que desempeña el bibliotecólogo de hoy, es el manejo de la información, dirigido al servicio del usuario, asumiendo a su vez liderazgo en la difusión sobre la esencia de la labor profesiónal, que permita la comprensión y el reconocimiento del silencioso trabajo del bibliotecólogo, concientizando y alertando a los tesponsables comprometidos en este quehacer, que si los valiosos documentos que muchas veces representan ingentes recursos invertidos carecen de tratamiento profesional, la situación inmediata será su desactualización, obsolescencia y por tanto, recurso mal empleado; y si consideramos que la información es considerado recurso estratégico para el desarrollo de toda actjvidad humana, que crece y se incrementa incontrolablemente en todo tipo de organizaciónes, necesitando la presencia de un profesional preparado pafar' \&emplifqudelicadanision'social de ser el puente entre la información y el usuario.

Si en los albores de la humanidad, el bibliotecario era considerado el guardián de libros, y luego en el siglo XIX éstos se hacen socialmente imprescindibles, a tal punto que "La sociedad democrática es hija del libro, [...] en donde "Las masas se abalanzan sobre los volúmenes con una urgencia casi respiratoria, como si fueran balones de oxígeno" . En la actualidad ya en el tercer milenio, este profesional con el apoyo de los últimos adelantos que la tecnología nos ofrece, se ha convertido en el facilitador no sólo del libro con los lectores, sino del encuentro de la información relevante y oportuna, con los usuarios, que en última instancia es a quienes nos debemos.

4. İdem, p. 67.

$$
\text { YLMEROTEQA DE LETRAS }
$$




\section{EL USUARIO DE LA INFORMACIÓN}

La búsqueda de una óptima formación profesional y el desempeño de la misma sobre la base de una educación permanente tiene por finalidad responder las exigencias de la sociedad (en sentido macro), pero que en última instancia pasa -en lo que concierne al bibliotecólogo- por una labor eficiente en el manejo de la información. Pero ¿a quién representa esta sociedad concebida en abstracto, receptora de todo este esfuerzo?, sin duda son los usuarios (hoy llamado clientes) en la medida que todo este trabajo apoyado en adecuados medios de formación de usuarios, posibilite la satisfacción de sus necesidades informativas, podremos afirmar categóricamente que estamos cumpliendo nuestra misión profesional, hecho que validará la actividad profesional en la sociedad.

\section{FORMACIÓN PROFESIONAL}

Los fines esenciales que cumple la Universidad, son las de impartir formación científica (adquirir conocimientos), técnica (destrezas y habilidades) y humanística (valores y actitudes). Al respecto el educador Jorge Capella escribe: "La misión de la universidad es la búsqueda y la comunicación del saber en todas sus expresiones, y para cumplir con esta misión la universidad, sea cual fuere el signojideologico de quienes la regentan, debería plantearse fines académico-epistemológicos, fines socio políticos y fines axiológicos, tratando de mantener "el equilibrio entre ellos"s. Sobre la base de estos enunciados, la formación del futuro bibliotecólogo tiene como objetivo lograr una sólida preparación que le permita responder al requerimiento de la sociedad, académicamente, estas exigencias buscan concretarse en la correspondencia que debe existir entre el perfil profesional (imagen-objetivo) y las necesidades de la sociedad (el mercado laboral).

Pera el caso de los profesionales en bibliotecología y ciencias de la información que forma la UNMSM, el perfil diseñado por primera vez con amplitud, luego de largos días de jornadas curriculares forma parte del nuevo plan curricular de 1996, comprende las áreas: profesional, académica, perso-

5 Capella Riera, Jorge. Una década en la educación peruana, 1980-1990. Reflexiones y propuestas. Lima: Ed. Cultura y Desarrollo, 1990, p. 340. 
nal humanística y de proyección social; y que señala que al concluir sus estudios el licenciado en Bibliotecología y Ciencias de la Información, será capaz de:

\section{Area profesional}

1. Diseñar, planificar, organizar, administrar y asesorar y evaluar rigurosa y creativamente sistemas y servicios de información en realidades diversas, en las que aplicará técnicas de mercadeo orientadas a su autofinanciamiento.

2. Utilizar, actualizar y proponer métodos, técnicas y procedimientos manuales, automatizados y de calidad total para el tratamiento y recuperación de la información y la adecuada transferencia de la misma.

3. Identificar y satisfacer las necesidades de información de los usuarios, así como promover y fomentar el uso de la información y la participación activa de los usuarios en los sistemas de información.

4. Conocer la existencia, forma de uso, límites, potencialidades de aplicación, condiciones de acceso, criterios de evaluación y tendencias en el desarrollo de los recursos y fuentes de información, formales y orales, manuales y automatizadas, públicas e inéditas y, en general, todos los materiales documentales que permitan proporcionar información a los usuarios. "Jorge Puccinelli Converso»

5. Interactuar en un entorno virtual, y de globalización informativa. Así como en equipos profesionales cooperativos y multidisciplinarios.

6. Desempeñarse como profesional liberar o dependiente en asesorías, consultorías, capacitación, evaluación, diagnósticos, empresas de servicios y cualquier estudio o proyecto relacionado con las Ciencias de la Información: Bibliotecología, archivología, museología y documentación; así como en sus áreas instrumentales, como lo son la informática y las telecomunicaciones aplicadas a la documentación.

7. Capacidad de análisis y síntesis en la elaboración de productos informativos. 
8. Conservar y restaurar los diferentes soportes en los que se encuentra la información.

9. Gerenciar la información de las diferentes áreas del conocimiento.

10. Conocer el idioma inglés como un curso instrumental indispensable para el manejo de la información.

Area personal

1. Demostrar sentido de organización, orden, responsabilidad, vocación de servicio, buen trato personal e iniciativa; así como observar una ética en el ejercicio profesional y personal sustentada sobre sólidos principios humanistas.

2. Adaptarse a un entorno tecnológico y conceptual marcado por el permanente cambio.

3. Fuidez y corrección en Ta comunicación oral y escrita.

4. Mostrar seguridad en sus conocimientos y capacidades para el ejercicio profesional.

5. Observar y actuar criticamente en dos procesos culturales y los problemas sociales.

Perfil diseñado sobre la base de la adquisición de conocimientos, capacidades, destrezas y aptitudes en el manejo de la información, el mismo que comprende, todo el proceso como ya se dijo líneas arriba de selección, tratamiento, recuperación, transferencia y control de la información, lo cual supone adquirir durante su formación profesional, competencias exigidas por el mercado, tales como la capacidad de diagnosticar, evaluar, diseñar, planificar y operacionalizar sistemas y unidades de información de todo tipo, tanto en organizaciones públicas como en las privadas.

Y si contrastamos con la realidad aquí y ahora, este diseño plasmado en el currículum de formación profesional, en algunos casos (los menos afortunadamente), constituye un objetivo, logro que muchas veces se encuentra restringido por las limitaciones propias del sistema educativo en nuestro 
país, que indudablemente depende de muchos factores, que bien puede ser tema de otro análisis, pero que tiende a concretarse en el ejercicio práctico, actividad fundamental que permite afianzar y mejorar las competencias del profesional, poniendo en práctica, desde el ámbito en que se encuentra, uno de los principios fundamentales de la educación de adultos (Montreal 1960), en la que se afirma que el hombre no cesa de aprender desde que nace hasta que muere, planteamiento reforzado por Isabel Olivera cuando sostiene, " $\mathrm{La}$ preparación efectiva para el siglo XXI requiere de una educación profesional que responda tanto a los cambios que se están produciendo ahora como a los que se están pronosticando, y que el resultado de ello sea un profesional que no sólo se anticipe al cambio, sino que él mismo sea un agente de cambio proactivo" , hecho que implica adoptar actitudes conducentes a la permanente mejora en la calidad profesional, dentro y fuera de las aulas universitarias, tendientes a lograr que la función del bibliotecólogo sea reconocido y valorado en la verdadera dimensión que ésta tiene y como dijeran los especialistas del marketing, lograr el posicionamiento de la carrera en la sociedad.

\section{EL AVANCE DE LA INFORMÄTICA}

El incesante avance en la última década de la informática y las telecomunicaciones (red telefónica, satélites de telecomunicaciones, fibra óptica, computadoras interconectadas, etc.), ha dado lugar que algunos profesionales enfrasquen su mayor preocupacion en tos aspectos tecnológicos ligados al manejo de la információn, dejando en un segunḑ "plano el análisis y la reflexión sobre la direccionalidad que debe asumir el trabajo bibliotecario a fin de superar las enormes barreras y dificultades que en países como el nuestro, limitan al usuario el acceso y la oportunidad a la información, olvidando que el derecho a la información constituye uno de los derechos humanos más importantes consagrados en la Constitución. Frente a este avance tecnológico, los especialistas recomiendan que el bibliotecólogo afronte este reto con la actualización y la permanente adaptación al cambio, sin perder de vista lo que en su momento alertara Páez Urdaneta, no caer en el síndrome de la tecnología informativa, hecho que "herramientaliza" la profesión.

6 Olivera R., Isabel. El profesional de la información del futuro: cambio y reconversión. Exposición. 
Y sobre el uso cada vez más generalizado de INTERNET, a tal punto que algunos vaticinan el fin de las bibliotecas al ser reemplazado por este medio que nos permite el acceso a las bases de datos de las grandes universidades, centros de investigación, a grandes bibliotecas etc., es oportuno resaltar el punto de vista de los especialistas, quienes afirman que existe una impresión errónea de que esta supercarretera de la información pueda llegar a sustituir y desplazar a las bibliotecas, centros de documentación, archivos, etc. por lo que es pertinente reproducir lo que nos dice sobre el peligro de la infoadicción, el gran filósofo argentino Mario Bunge: "Información o mensaje no es lo mismo que conocimiento, Internet difunde no sólo verdades, sino también falsedades e incluso mentiras, pero sobre todo banalidades. [...] no se distingue de otros medios de comunicación masivo.. Todos estos medios se distinguen de las publicaciones cientificas, cuyo material es pasado a filtro antes de ser publicado [...] en Internet no hay filtro, pasa tanto basura como joya $[. .$.$] no hay filtro porque no hay estándares y porque la decisión de$ publicar o no queda librada al asbitrio del individuo, sin discusión con colegas, ni, menos aún, con maestros [...]. Internet no podrá desplazar a la biblioteca pese a las profesías que se vienen propalando desde hace años"?. Asimismo el periodista Gabriel Valle agrega: nunca antes un escenario había sido capaz de albergar a tan dispares actores, que representan la locura y la cordura, la ciencia y la necedad, lo sublime y lo grotesco, lo sano y lo morboso, lo noble y lo ruin, en donde la caudalosa información, medida en millones de metros cúbicos por segundo y ofrecida con tempestuoso desorden, puede llevar al desconcierto y al vertigo. "Jorge Puccinelli Converso" 


\section{BIBLIOGRAFIA}

BUNGE, Mario

1996

"¿Adónde lleva? Autorruta de la información”, El Comercio; Suplemento dominical. 10 de noviembre, p. 9.

CAPELLA RIERA, Jorge

1990

Una década en la educación peruana, 1980-1990. Reflexiones y propuestas. Lima: Editorial Cultura y Desarrollo.

FERNÁNDEZ-ABALLI, Isidro

1996 "La información: un recurso esencial para el desarrollo". En: INFOLAC. Vol. 9, $\mathrm{N}^{\circ} 3$.

GUINCHAT, Claire

1990

Introducción general a las ciencias y técnicas de la información y documentación. Madrid: UNESCO.

OLIVERA R., Isabel

1994

El profesional de la información del futuro: cambio y reconversión. Exposición de la autora en la Mesa Redonda sobre Formación Profesional de las Jornadas del Colegio de Bibliotecólogos del Perú 17-18 de noviembre.

ORTEGA Y GASSET, Joserge Puccinelli Converso "

1962 Misión del bibliotecario. Madrid: Revista de Occidente.

PÁEZ URDANETA, Iraset

1992

Gestión de la inteligencia, aprendizaje tecnológico y modernización del trabajo informacional. Retos y oportunidades. Caracas: Instituto de Estudios del Conocimiento de la Universidad Simón Bolívar. Consejo Nacional de Investigación Cientìfica y Tecnológica.

PONJUAN DANTE, Gloria

1998

Gestión de la información en las organizaciones. Centro de Capacitación en Información. Santiago de Chile: Universidad de Chile. 
被 